\title{
Ni-doped Carbon Nanofilaments (Ni-CNF): Preparation and Use as Reforming Catalyst
}

\author{
Nicolas Abatzoglou, Carmina Reyes Plascencia \\ Chemical and Biotechnological Engineering, Université de Sherbrooke, \\ 2500 boul. Université, Sherbrooke, Quebec, Canada J1K 2R1 \\ Nicolas.Abatzoglou@USherbrooke.ca; Carmina.Reyes.Plascencia@USherbrooke.ca
}

\begin{abstract}
The use of nanocarbons as heterogeneous catalyst support offers the possibility of achieving well-dispersed and thermally-stable catalysts. Because of their low internal diffusion resistance and relatively high specific surface, carbon nanotubes and carbon nanofilaments (CNF) are of special interest. This work reports on a CNF functionalization endeavour aimed at producing Ni-CNF as steam-reforming catalysts. Catalytic activity was studied parametrically on diesel and biodiesel steam reforming. Fresh and spent catalysts were investigated by scanning and transmission electron microscopy to visualize their morphology, by thermogravimetric analysis to evaluate metal (Ni) load, by Xray diffraction to assess the presence of and changes in crystalline (and amorphous) phases, and by Brunauer Emmet and Teller analysis to appraise the catalyst surfaces. Reactants conversion and reformate composition (product yields) were reported over time-on-stream under various reaction conditions. Finally, CNF-supported Ni-catalysts were compared to equivalent multiwall carbon nanotube (MWCNT)-supported catalysts (Ni-MWCNT). The results demonstrated excellent initial reforming activity which declined relatively rapidly over time for Ni-CNF. The fast deactivation observed was due to CNF instability under reforming conditions which led to nanometrically-distributed $\mathrm{Ni}$ grain sintering and, consequently, loss of specific surface.
\end{abstract}

Keywords: Nanocatalysis, Carbon nanofilaments, Diesel, Biodiesel, Steam reforming.

(C) Copyright 2015 Authors - This is an Open Access article published under the Creative Commons Attribution License terms (http://creativecommons.org/licenses/by/3.0). Unrestricted use, distribution, and reproduction in any medium are permitted, provided the original work is properly cited.

\section{Introduction}

Heterogeneous, metal-based, supported catalysis is being widely investigated - both industrially and experimentally - for $\mathrm{H} 2$ production through steam (SR) or dry reforming (DR), autothermal reforming or partial oxidation [1], [2].

Noble and transition metals are known for their high catalytic activities in these reactions. Generally, such activities decrease in the following order: $\mathrm{Co}, \mathrm{Ru}$, $\mathrm{Rh}, \mathrm{Ni}, \mathrm{Pt}, \mathrm{Re}, \mathrm{Ir}, \mathrm{Pd}, \mathrm{Cu}, \mathrm{W}, \mathrm{Fe}, \mathrm{Mo}$ [3]. Among the above metals, $\mathrm{Ni}$ is the preferred commercial option because its activity is as high as the best noble metal, but its life cycle is usually shorter due to its higher than noble metal tendency to dissolve carbon, leading to carbonrelated deactivation [3], [4].

Catalyst preparation protocols as well as the nature and morphology of metal-supporting materials are critical in terms of catalytic formulation activity, selectivity and stability [5]. Relatively recent publications [6], [7], [8] have reviewed this field and have provided considerable insights into the role of supporting materials.

In the industry, the 3 most common types of catalyst support are based on alumina, silica, and carbon [9], [10]. More specifically, the literature on carbon materials as support of reforming catalysts can be summarized as follows: SR of methanol over $\mathrm{Ni}$ $\mathrm{Cu} / \mathrm{CNT}$ (carbon nanotubes) [11], catalytic reforming of dimethoxymethane over $\mathrm{Cu} / \mathrm{CNF}$ (carbon nanofilaments) and $\mathrm{Ni} / \mathrm{CNF}$ [12], DR of ethanol over $\mathrm{FeC}_{\mathrm{x}} / \mathrm{CNF}$ [13], [14], DR of methane over metallurgical coke and activated carbons [15], oxidative SR of ethanol over Co/CNF [16], SR of propane over Ni/MWCNT (Nifunctionalized multiwall carbon nanotubes) [17], SR of bio-oil over Ni/CNF [18].

Carbon materials as metal supports are of particular interest because of their properties: high specific surface, high resistance to acidic and alkaline 
media, thermal stability, possibility of high metal load dispersion and easier metal recuperation than in ceramic supports through gasification at the end of the catalyst's life.

Carbon nanostructures, especially CNT, have attracted the attention of the scientific community because of their highly-ordered structure, relatively high specific surface, near-zero internal mass transfer resistance when they are treated properly, and their capacity to nanodisperse metal loads.

CNT have been studied as catalytic support for reactions, such as hydrogenation [19], [20] and dehydrogenation [21]. Seelam et al. [22] reported that CNT utilization supported $\mathrm{Ni}$ catalysts $(10 \%$ of $\mathrm{Ni}$ ) in carrying out ethanol SR. Below $300^{\circ} \mathrm{C}$, Ni-CNT catalyst gave the same ethanol conversion as conventional $\mathrm{Ni}$ $\mathrm{Al}_{2} \mathrm{O}_{3}$ with $16.6 \% \mathrm{w} / \mathrm{w} \mathrm{Ni}$. At temperatures (Ts) above $300^{\circ} \mathrm{C}$, conversion with $\mathrm{Ni}-\mathrm{CNT}$ is $98 \%$ higher than that obtained with $\mathrm{Ni}-\mathrm{Al}_{2} \mathrm{O}_{3}$ as catalyst.

CNF are graphitic carbon filamentary structures with diameters ranging from a few to some hundred nanometres [23]. Their main difference from CNT is that the graphitic sheets are not concentric cylinders evolving along the main axis, but are rather arranged conically. Moreover, CNF generally contain more surface defects than CNT, which leads to higher heteroatoms and metal functionalization capacity due to higher electrical charge density [24].

According to the literature, $\mathrm{CNF}$ have served as catalyst support for different reactions, namely, hydrogenation [25], hydroformulation [26], and reforming [12]. Da Silva et al. [16] performed oxidative SR of ethanol with Co-CNF catalyst; they reported ethanol conversion as high as $85 \%$ at $500^{\circ} \mathrm{C}$. Although catalysts with particles smaller than $4 \mathrm{~nm}$ show deactivation through metal oxidation, those with bigger particles $(16 \mathrm{~nm})$ remain stable over $24 \mathrm{~h}$.

Recently, CNF were considered as catalytic support for bio-oil SR by Xu et al. [18], who reported $80 \%$ carbon conversion with $\mathrm{Ni}$ load of $22 \%$. Nevertheless, deactivation over time was significant.

Abatzoglou et al. [27] have developed and patented CNF production at various scales [28]. Ethanol DR is the basis of this protocol. CNF so-derived, without any modifications, present catalytic properties for the same reaction, attributed to their ferric carbide content of CNF $[13,14]$.

In this work, CNF have been modified to incorporate metallic $\mathrm{Ni}$ particles. The catalytic activity of Ni-CNF in diesel and biodiesel SR has been studied and compared to that of similar MWCNT.

\section{Experimental Methodology}

\section{1. CNF Production and Functionalization}

CNF have been produced with an ethanol $\left(\mathrm{CO}_{2}\right)$ DR protocol, described in an earlier publication and patent by the corresponding author's research group [27]. The catalyst was previously heat-treated under gaseous mixture flow $\left(99 \% \mathrm{Ar}\right.$ and $\left.1 \% \mathrm{O}_{2}\right)$ at $800^{\circ} \mathrm{C}$ for $1 \mathrm{~h}$ to partially oxidize the surface $[13,14]$. The reaction was carried out in a fixed-bed isothermal quartz reactor at $550^{\circ} \mathrm{C}$. Molar ratio of the reactants in the feed was $\mathrm{CO}_{2} / \mathrm{C}_{2} \mathrm{H}_{6} \mathrm{O}=1$ and the flow rate was adjusted to achieve gas-hourly-space-velocity of 2,700 $\mathrm{ml} / \mathrm{h} / \mathrm{g}_{\text {cat }}$ CNF were recovered after the reaction and analyzed.

The CNF were acid-treated to improve surface properties prior to $\mathrm{Ni}$ functionalization. A $4-\mathrm{kmol} / \mathrm{m}^{3}$ water solution of nitric acid $\left(\mathrm{HNO}_{3}\right)$ was used for $3 \mathrm{~h}$ under reflux. This treatment [27] was aimed at decreasing hydrophobicity and increasing CNF polarity by the addition of oxygenated groups, thus improving interaction between the CNF and Ni particles. Moreover, during treatment, the iron carbide nanoparticles, formed in CNF tips during their production process, were essentially removed by acid treatment, which was followed by washing with distilled water until $\mathrm{pH}$ neutralization and overnight drying at $120^{\circ} \mathrm{C}$. These conditions were found to be optimal for the metal charge needed after a series of experiments performed at different temperatures (Ts) and contact times between the acid and CNF.

$\mathrm{Ni}$-functionalization was concluded according to a wet impregnation method with $\mathrm{Ni}\left(\mathrm{NO}_{3}\right)_{2} \bullet 6 \mathrm{H}_{2} \mathrm{O}$ as $\mathrm{Ni}$ precursor. A final metallic Ni mass load of $5 \% \mathrm{w} / \mathrm{w}$ was chosen for reforming experiments. This choice was based on a previous publication [29] with other $\mathrm{Ni}$ based catalytic formulations. After impregnation, the so-treated $\mathrm{CNF}$ were dried overnight at $120^{\circ} \mathrm{C}$ and calcined at $290^{\circ} \mathrm{C}$ for $8 \mathrm{~h}$ under inert (Ar) atmosphere. The resulting NiO-containing solid was reduced inside the reformer (SR reactor) just before its use as catalyst of diesel SR reaction (Ni-CNF). The reduction conditions were $450^{\circ} \mathrm{C}$ for $1 \mathrm{~h}$ in a gaseous mixture flow of $10 \% \mathrm{H}_{2}$ 90\% Ar. 


\section{2. Catalyst Characterization}

CNF and Ni-CNF morphology was examined by a Hitachi S-4700 high-resolution field emission gun scanning electron microscopy (FEG-SEM).

The effect of acid treatment on CNF structure was evaluated qualitatively with deposited metallic $\mathrm{Ni}$ particle localization and size distribution studied by transmission electron microscopy (TEM). TEM images were obtained by a Hitachi H-7500 TEM at 60 and 120 $\mathrm{kV}$. TEM analyses were conducted on (1) CNF, (2) CNF after acid treatment, (3) CNF after Ni-impregnation and calcinations, and (4) Ni-CNF after SR.

For all microscopy analyses, the samples were dispersed in methanol in an ultrasonic bath, and then transferred to sample holders. In SEM, the sample holder was a silicon film, and, in TEM, the sample was transferred to a perforated, carbon-supported film on a 300-mesh gold TEM grid.

Specific CNF surface area before and after acid treatment was evaluated by multipoint Brunauer Emmet and Teller (BET) analyzer, with nitrogen absorption in an accelerated surface area and porosimetry system (Micrometrics ASAP 2020).

$\mathrm{Ni}$ oxidation state after calcination was assessed by X-ray diffractometry (XRD) in an X'pert Pro MRD from PANalytical with monochromator. Analysis involved $\mathrm{K} \alpha 1$ radiation of $\mathrm{Cu}$ at $40 \mathrm{kV}$ and $30 \mathrm{~mA}$.

$\mathrm{NiO}$ concentration in impregnated and calcined CNF was ascertained quantitatively by thermogravimetric analysis in a SETARAM SETSYS 24 system with $20 \%$ flow of 02 in Ar from ambient T up to $1,000^{\circ} \mathrm{C}$. Metal mass load in the $\mathrm{CNF}$ was measured from mass difference between the initial sample and sample mass at the end of CNF gasification. The same analysis was undertaken on CNF after acid treatment to estimate nano-iron carbide amounts on CNF.

To determine NiO load reduction, T-programmed reduction (TPR) tests were performed under gaseous mixture flow of $10 \% \mathrm{H}_{2}-90 \% \mathrm{Ar}$ (molar) at the $0^{\circ}$ $1,000^{\circ} \mathrm{C}$ T interval in a Micrometrics Chemisorb 2750 system with thermal conductivity detector.

\section{3. Experimental Reforming Set-Up}

Diesel and biodiesel SR tests were conducted in a fixed bed reactor illustrated in Figure 1. The reactor was made of quartz with an inner diameter of $0.46 \mathrm{~cm}$ and length of $122 \mathrm{~cm}$. The catalyst was dispersed uniformly in quartz wool placed at the reactor center. Catalytic bed height was $7.5 \mathrm{~cm}$, and the catalyst's mass was variable.

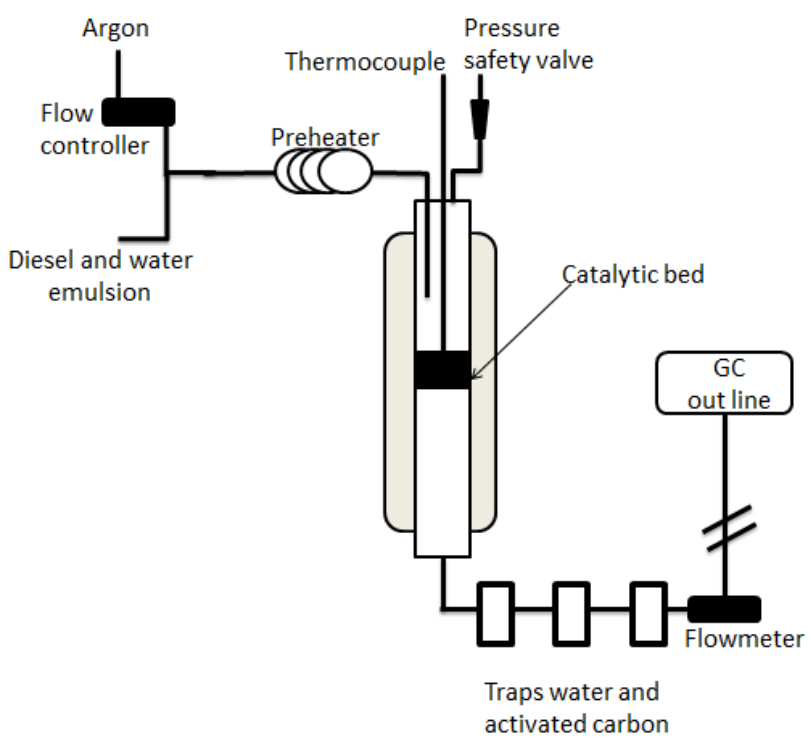

Figure 1. Reactor set-up for diesel SR

Emulsified mixtures of preselected diesel or biodiesel/water mass ratios were fed into the reformer, by precalibrated peristaltic pump. The $\mathrm{H}_{2} \mathrm{O} / \mathrm{C}$ molar ratio was 1.9 for all reactions. Ar flow preheated at $550^{\circ} \mathrm{C}$ was the carrier gas along with diesel emulsion feed. The desired reaction $\mathrm{T}$ was controlled by an oven and monitored with a 10-measurement-point thermocouple. Reactions were carried out at atmospheric pressure.

Exit flow was monitored with a flow meter, and exit gas product composition was analyzed by off-line Varian CP-3800 gas chromatography with sampling every $20 \mathrm{~min}$.

Experimental conversion was calculated with Equation (1), where ' $N$ ' was the number of moles, Y was the number of carbons in the surfactant, 'a' was the number of carbons, ' $b$ ' was the number of hydrogen atoms, and ' $c$ ' was the number of oxygen atoms in the target molecule.

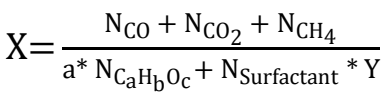

\section{Results and Discussion}

\section{1. Ni Impregnation}

CNF point of zero charge was determined by Regalbuto's protocol [30] with $\mathrm{pH}=8.5$. Based on this result, metal impregnation was done at 5.5 in distilled water without Ni impregnation. This result dictated the need for acid treatment. 
Metal impregnation was preceded by acid treatment to incorporate polar groups on CNF and fix the metal particles. It has been reported that nitronium ion was able to attack aromatic compounds [31] and incorporate oxygenated groups.

Acid treatment also removed iron carbide nanoparticles remaining in the CNF, as shown in Figure $2 a$.

After the wet impregnation and calcination steps, $\mathrm{NiO}$ particles were observed on the surface and inside CNF internal (central) channels (Figure 2b). Presence of the metal was confirmed by XRD (results not reported in this paper because of space limitations.

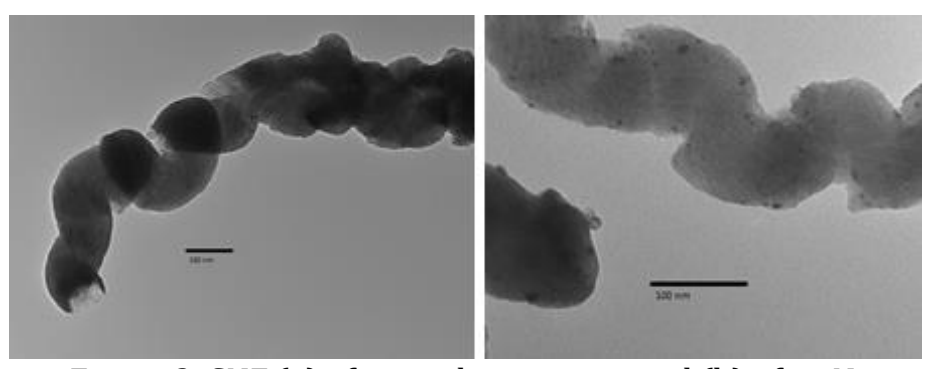

Figure 2. CNF (a) after acid treatment, and (b) after Ni impregnation and calcination.

Particle size distribution was analyzed by TEM with sample size containing about 80 particles. Soevaluated Ni-containing particle size average was 5.3 $\mathrm{nm}$, and mode of distribution was $3 \mathrm{~nm}$.

Specific surface area was not significantly affected by the impregnation process. CNF without modifications showed BET surface area of $173.4 \mathrm{~m}^{2} / \mathrm{g}$. BET was measured to be $198.1 \mathrm{~m}^{2} / \mathrm{g}$ after acid treatment and $193.4 \mathrm{~m}^{2} / \mathrm{g}$ after impregnation. The small mass-specific surface area change (increase of about $10 \%$ ) after acid treatment was attributed to the removal of iron carbide particles and the consequent availability of CNF internal channels present in fishbone-type CNF.

\section{2. Diesel SR}

Space velocity (SV) was studied by modifying catalyst mass. Diesel SR was performed at $760^{\circ} \mathrm{C}$. Changes in mass-hourly-space-velocity (MHSV) and its effect on conversion are reported in Table 1.

Diesel SR conversion was almost complete (98.5\%) for MHSV below 1.3. Carbon conversion decreased above this SV. Figure 3 presents the composition of syngas and exit flow.
SR could be divided into 3 zones: 1 . the stabilization zone; characterized by change in syngas composition for gas homogenization inside the reactor; 2 . the stable reaction rate zone and 3 . The deactivation zone - characterized by change in syngas composition and decreased exit flow.

Table 1. Mass catalyst effect on diesel SR.

\begin{tabular}{|c|c|c|c|c|}
\hline $\begin{array}{c}\text { Catalyst } \\
\text { mass (g) }\end{array}$ & $\begin{array}{c}\text { Reaction } \\
\text { time (h) }\end{array}$ & $\begin{array}{c}\text { MHSV } \\
\left(\mathrm{g} \mathrm{g}^{-1} \mathrm{~h}^{-1}\right)\end{array}$ & $\begin{array}{c}\text { Mass } \\
\text { balance } \\
\text { error (\%) }\end{array}$ & $\mathrm{X}_{\mathrm{C}}$ \\
\hline 1.5 & 6.6 & 2.8 & -2.9 & 61.4 \\
\hline 3 & 6.8 & 1.3 & 6.4 & 98.5 \\
\hline 6 & 5.6 & 0.72 & 8 & 101 \\
\hline 9 & 5.6 & 0.75 & -3.5 & 99.3 \\
\hline
\end{tabular}

So-produced syngas composition was compared to that at thermodynamic equilibrium; the latter was calculated by Gibbs minimization with FactSage software. Measured $\mathrm{H}_{2}$ and $\mathrm{CO}_{2}$ yields were higher than those at equilibrium. This was attributed to the fact that the water-gas-shift-reaction was not at equilibrium and was corroborated by higher CO content.

Table 2. Temperature effect on diesel SR.

\begin{tabular}{|c|c|c|c|c|}
\hline $\begin{array}{c}\text { Temperature } \\
\left({ }^{\circ} \mathrm{C}\right)\end{array}$ & $\begin{array}{c}\text { Reaction } \\
\text { time }(\mathrm{h})\end{array}$ & $\begin{array}{c}\text { MHSV } \\
\left(\mathrm{g} \mathrm{g}^{-1} \mathrm{~h}^{-1}\right)\end{array}$ & $\begin{array}{c}\text { Mass } \\
\text { balance } \\
\text { error (\%) }\end{array}$ & $\mathrm{X}_{\mathrm{C}}$ \\
\hline 700 & 6.9 & 1.4 & -4.2 & 79 \\
\hline 720 & 6.7 & 1.3 & -5.3 & 91 \\
\hline 740 & 7.1 & 1.2 & -5.6 & 97 \\
\hline 760 & 6.8 & 1.3 & 6.4 & 98 \\
\hline
\end{tabular}

The $\mathrm{T}$ effect was evaluated in the $700^{\circ}$ to $760^{\circ} \mathrm{C}$ range at constant MHSV. In this study, $3 \mathrm{~g}$ of catalysts were tested, and conversions are presented in Table 2 .

Under the remaining, constant experimental conditions, complete Carbon conversion was obtained only at $\mathrm{T}$ above $740^{\circ} \mathrm{C}$. Moreover, the tested catalyst showed relatively fast deactivation.

To investigate the cause of catalytic deactivation, the catalysts used were analyzed by TEM, and the micrographs so-obtained appear in Figure 4. Significant disintegration of CNF support and sintering of metallic particles were evident. These observations lead to the conclusion that the less ordered parts of CNF were gasified via reactions similar to diesel SR. This conclusion was corroborated by the fact that Carbon 
mass balance closures were difficult because the calculations were biased by CNF consumed. Thus, the less ordered sections of CNF were gasified/reformed at the same time as diesel, since it was not possible to precisely know whether the conversion of CNF carbon the diesel carbon conversion was biased.

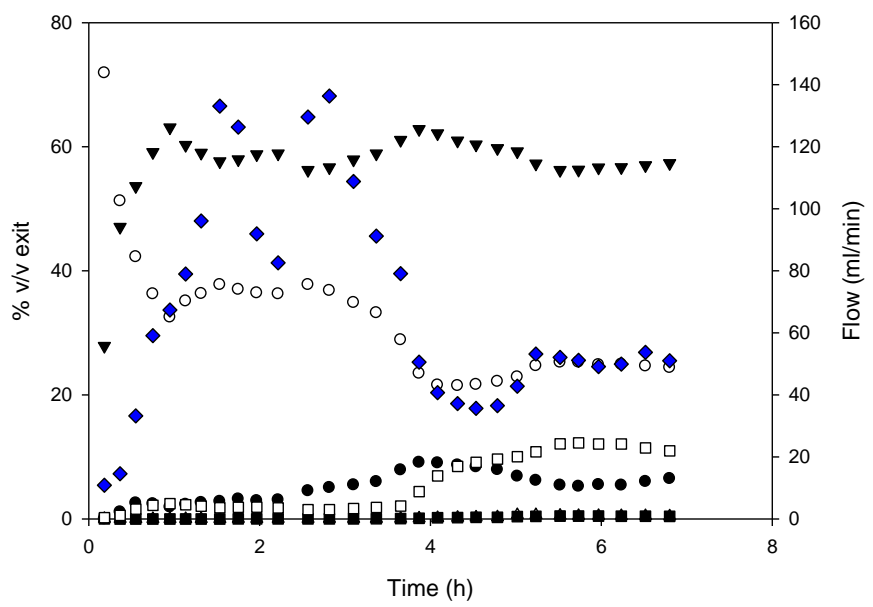

Figure 3. Diesel SR syngas composition at $760^{\circ} \mathrm{C}$. $-\mathrm{CO}_{2}, \mathrm{OCO}, \boldsymbol{\nabla} \mathrm{H}_{2}, \Delta \mathrm{C}_{2} \mathrm{H}_{4}, \square_{2} \mathrm{H}_{6}, \square \mathrm{CH}_{4}, \diamond$ Flow

These results are well-supported by the literature. Catalytic carbonaceous materials are gasified at $427^{\circ} \mathrm{C}$ in reducing atmosphere [10] while MWCNT start to decompose under inert atmosphere at $800^{\circ} \mathrm{C}$ [32]. This $\mathrm{T}$ is expected to be lower for CNF because the quantity of defects is higher, and the presence of metallic particles increases their reactivity.

Changes in particle size were calculated by measuring 80 particles in fresh and used catalysts via TEM. The calculations show that, in $760^{\circ} \mathrm{C}$ experiments, average particle size changed from 5.3 to $31 \mathrm{~nm}$.

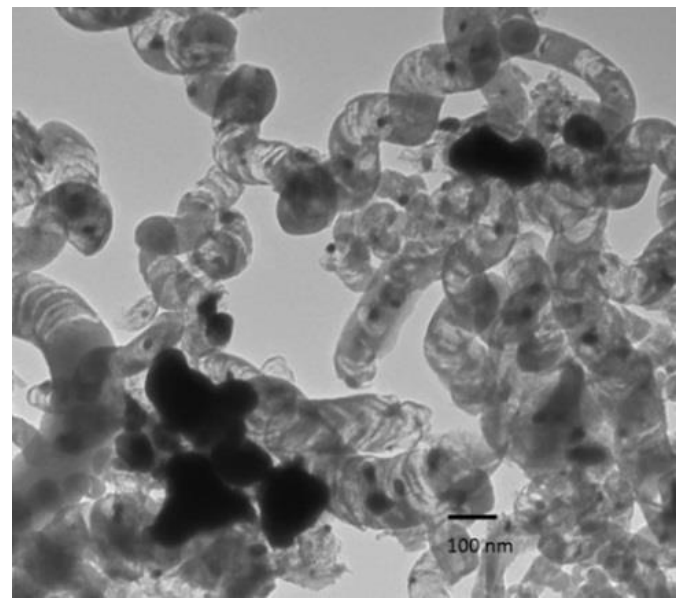

Figure 4. Ni-CNF after diesel SR.

\section{3. Biodiesel SR}

Biodiesel SR reactions over $\mathrm{Ni}-\mathrm{CNF}$ were studied at different Ts with $3 \mathrm{~g}$ of catalyst at the same MHSV. The results are presented in Table 3 .

Table 3. T effect on biodiesel SR.

\begin{tabular}{|c|c|c|c|c|}
\hline $\begin{array}{c}\text { Temperature } \\
\left({ }^{\circ} \mathrm{C}\right)\end{array}$ & $\begin{array}{c}\text { Reaction } \\
\text { time (h) }\end{array}$ & $\begin{array}{c}\text { MHSV } \\
\left(\mathrm{g} \mathrm{g}^{-1} \mathrm{~h}^{-1}\right)\end{array}$ & $\begin{array}{c}\text { Mass } \\
\text { balance } \\
\text { error (\%) }\end{array}$ & $\mathrm{X}_{\mathrm{C}}$ \\
\hline 670 & 6.8 & 1.3 & 0.0232 & 80.2 \\
\hline 680 & 7.4 & 1.3 & -4.4 & 83.5 \\
\hline 700 & 7.2 & 1.4 & -2.4 & 99.1 \\
\hline 760 & 5.4 & 1.3 & -1.57 & 91.6 \\
\hline 760 & 12 & 1.2 & -2.07 & 90.2 \\
\hline 800 & 7 & 1.1 & -2.81 & 94 \\
\hline
\end{tabular}

Maximal conversion occurred at $700^{\circ} \mathrm{C}$. At higher Ts, conversion decreased and was attributed to faster CNF destruction with consequent metal content sintering.

Syngas composition and exit flow at $700^{\circ} \mathrm{C}$ and $800^{\circ} \mathrm{C}$ are reported in Figure 5. Decreased flow indicates lower $\mathrm{C}$ conversion and, therefore, catalyst deactivation. At $700^{\circ} \mathrm{C}$, the deactivation process started after $6 \mathrm{~h}$, and, at $800^{\circ} \mathrm{C}$, after $4.5 \mathrm{~h}$ of time-on-stream.

TEM analysis, not presented here for reasons of brevity, was similar to that in Figure 4, and showed metal sintering phenomenon taking place to a greater extent at higher Ts.

\section{4. Comparison of CNF and MWCNT}

MWCNT were utilized to compare the stability of this type of material with CNF. The catalyst was prepared with the same protocol as for CNF, and included acid treatment, wet impregnation, calcination and reduction under the same conditions.

The syngas composition obtained with both supports was similar, but, as seen in Figure 6, MWCNTsupported catalysts presented slower deactivation rates.

$\mathrm{Ni}-\mathrm{CNF}$ deactivation at $760^{\circ} \mathrm{C}$ commenced after 2 $\mathrm{h}$ of time-on-stream, while Ni-MWCNT started at $3 \mathrm{~h}$. As a consequence, overall Carbon conversion, presented in Table 4, was higher in the case of Ni-MWCNT.

Although MWCNT structure was rather stable, the metallic Ni particles also suffered significant sintering during the reaction. With the same procedure based on the measurement of 80 particles, we estimated that 
average particle size changed from $3 \mathrm{~nm}$ before reaction to $43 \mathrm{~nm}$ after reaction.

\section{$700^{\circ} \mathrm{C}$}
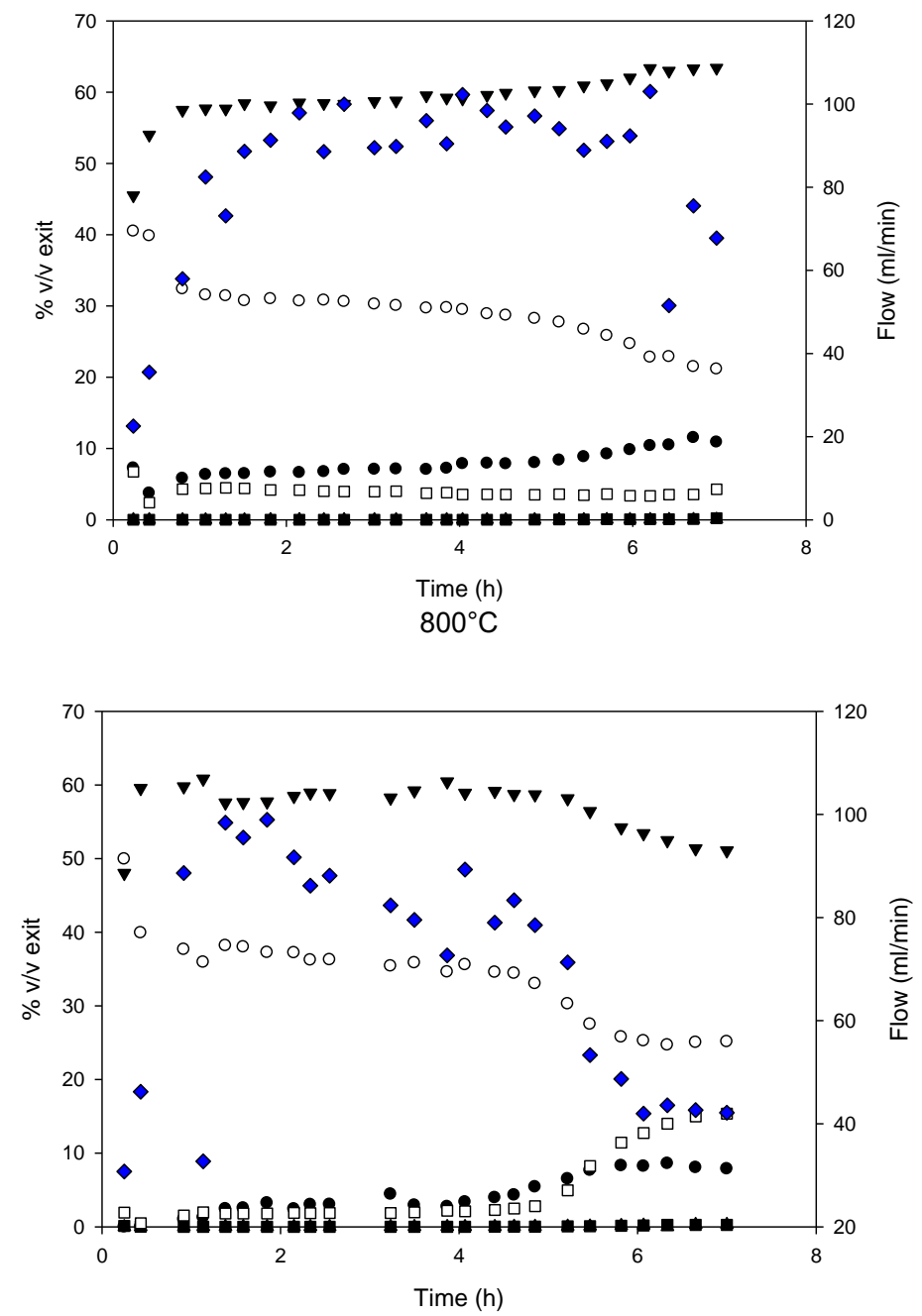

Figure 5. Biodiesel SR syngas composition at $700^{\circ} \mathrm{C}$, and $800^{\circ} \mathrm{C}$.

- $\mathrm{CO}_{2}, \mathrm{OCO}, \boldsymbol{\nabla} \mathrm{H}_{2}, \Delta \mathrm{C}_{2} \mathrm{H}_{4}, \mathrm{C}_{2} \mathrm{H}_{6}, \square \mathrm{CH}_{4}, \diamond$ Flow

Table 4. Diesel SR with CNF and MWCNT.

\begin{tabular}{|c|c|c|c|c|}
\hline Sample & $\begin{array}{c}\text { Reaction } \\
\text { time }(\mathrm{h})\end{array}$ & $\begin{array}{c}\text { MHSV } \\
\left(\mathrm{g} \mathrm{g}^{-1} \mathrm{~h}^{-1}\right)\end{array}$ & $\begin{array}{c}\text { Mass balance } \\
\text { error (\%) }\end{array}$ & $\mathrm{X}_{\mathrm{C}}$ \\
\hline CNF & 6.6 & 2.8 & -2.9 & 61.4 \\
\hline MWCNT & 4.6 & 2.8 & 0.82 & 94 \\
\hline
\end{tabular}

\section{Conclusions}

Although this work did not provide proof that the nanocatalyst formulations tested were sustainable, the conclusions are highly useful for future work on catalytic supports like CNF and MWCNT. Thus:
- Acid treatment of these supports is a crucial step for subsequent, efficient functionalization with metals like Ni. The insertion of polar groups in carbon structures is vital to the chemical anchoring of desired metal particles.

- The results reveal that Ni-CNF is an active catalyst for diesel and biodiesel SR.

- Nevertheless, catalyst deactivation is relatively fast and decreases Carbon conversion over timeon-stream.

- The observed catalytic deactivation is due to metallic part sintering caused by support gasification.

- Finally, MWCNT are more stable in SR conditions, but significant sintering deactivation also occurs.

MWCNT's
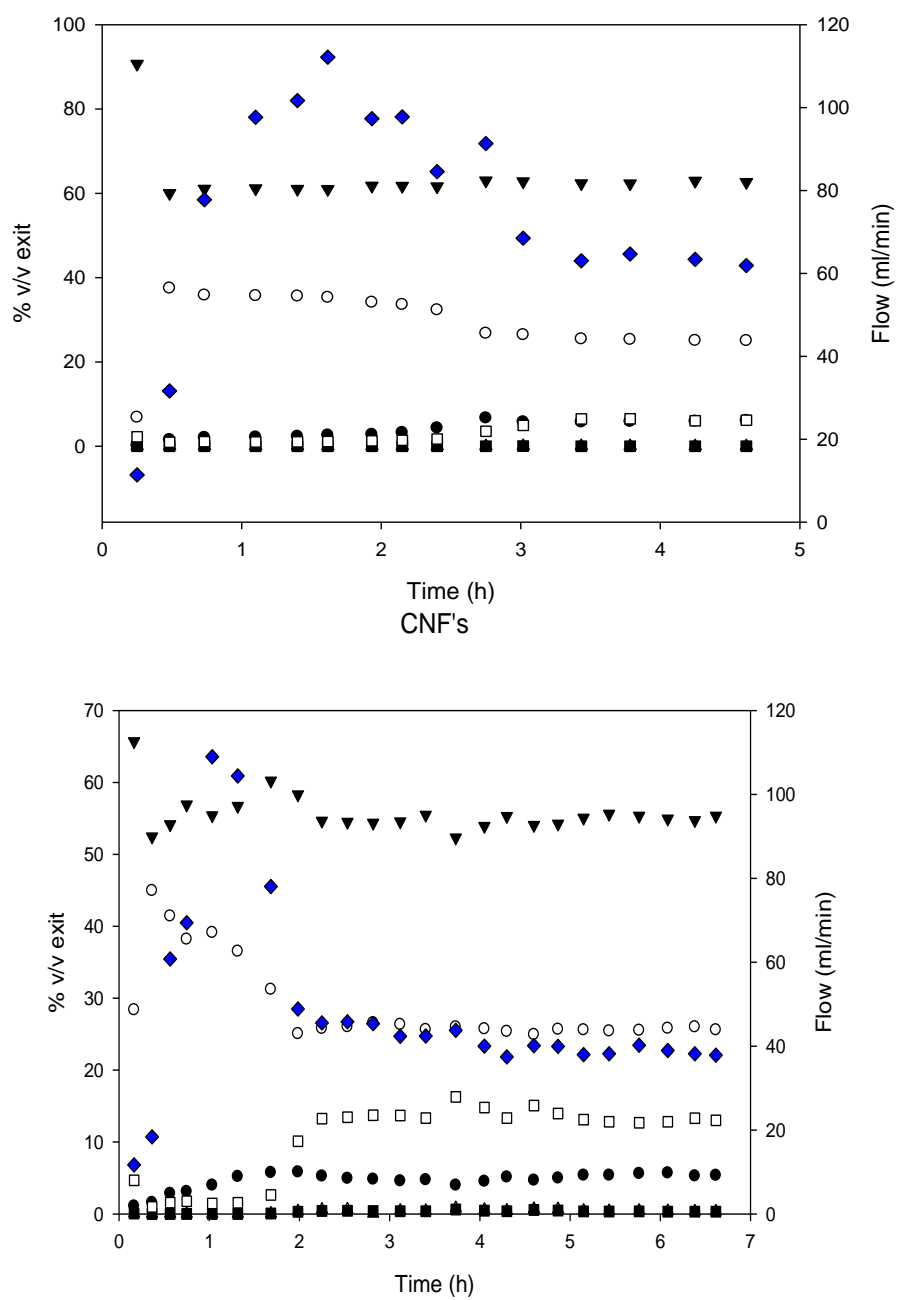

Figure 6. Diesel SR syngas composition at $760^{\circ} \mathrm{C}$ : (a) MWCNT and (b) CNF.

$\mathrm{CO}_{2}, \mathrm{OCO}, \boldsymbol{\nabla} \mathrm{H}_{2}, \Delta \mathrm{C}_{2} \mathrm{H}_{4}, \square \mathrm{C}_{2} \mathrm{H}_{6}, \square \mathrm{CH}_{4}, \diamond$ Flow 


\section{Acknowledgements}

This work was made possible by financial support from the Natural Sciences and Engineering Research Council of Canada's Solid Oxide Fuel Cell (SOFC) Network and by Canada's BioFuelNet National Center of Excellence. The technical contributions of Henri Gauvin and the personnel of the Universite de Sherbrooke's Centre de caractérisation des matériaux (CCM) are gratefully acknowledged.

\section{References}

[1] Q. Ming, T. Healey, L. Allen and P. Irving, "Steam reforming of hydrocarbon fuels," Catalysis Today, vol. 77, no. 1-2, pp. 51-64, 2002.

[2] D. J. Moon, "Hydrogen production by catalytic reforming of liquid hydrocarbons," Catalysis Surveys from Asia, vol. 15, no. 1, pp. 25-36, 2010.

[3] H. F. Abbas and W. M. A. Wan Daud, "Hydrogen production by methane decomposition: a review," International Journal of Hydrogen Energy, vol. 35, no. 3, pp. 1160-1190, 2010.

[4] C. H. Bartholomew, "Mechanisms of catalyst deactivation," Applied Catalysis A: General, vol. 212, no. 1-2, pp. 17-60, 2001.

[5] M. K. van der Lee, A. Jos van Dillen, J. H. Bitter and K. P. de Jong, "Deposition precipitation for the preparation of carbon nanofiber supported nickel catalysts," Journal of the American Chemical Society, vol. 127, no. 39, pp. 13573-13582, 2005.

[6] J. Gao, Z. Hou, H. Lou and X. Zheng, "Dry reforming," in Fuel Cells: Technologies for Fuel Processing, Elsevier, 2011, pp. 191-221.

[7] E. Ruckenstein and Y. H. Hu, "Role of support in $\mathrm{CO} 2$ reforming of $\mathrm{CH}_{4}$ to syngas over Ni catalysts," Journal of Catalysis, vol. 162, no. 2, pp. 230-238, 1996.

[8] M. H. Youn, J. G. Seo, K. M. Cho, J. C. Jung, H. Kim, K. W. La, D. R. Park, S. Park, S. H. Lee and I. K. Song, "Effect of support on hydrogen production by auto-thermal reforming of ethanol over supported nickel catalysts," Korean Journal of Chemical Engineering, vol. 25, no. 2, pp. 236-238, 2008.

[9] B. Fidalgo and J. Á. Menéndez, "Carbon materials as catalysts for decomposition and $\mathrm{CO}_{2}$ reforming of methane: a review," Chinese Journal of Catalysis, vol. 32, no. 1-2, pp. 207-216, 2011.

[10] F. Rodríguez-Reinoso, "The role of carbon materials in heterogeneous catalysis," Carbon, vol. 36, no. 3, pp. 159-175, 1998.

[11] P. H. Liao and H. M. Yang, "Preparation of catalyst $\mathrm{Ni}-\mathrm{Cu} / \mathrm{CNTs}$ by chemical reduction with formaldehyde for steam reforming of methanol," Catalysis Letters, vol. 121, no. 3, pp. 274-282, 2007.

[12] Y. Fu and J. Shen, "Production of hydrogen by catalytic reforming of dimethoxymethane over bifunctional catalysts," Journal of Catalysis, vol. 248, no. 1, pp. 101-110, 2007.

[13] S. Jankhah, N. Abatzoglou and F. Gitzhofer, "Thermal and catalytic dry reforming and cracking of ethanol for hydrogen and carbon nanofilaments' production," International Journal of Hydrogen Energy, vol. 33, no. 18, pp. 4769-4779, 2008.

[14] S. Jankhah, N. Abatzoglou, F. Gitzhofer, J. Blanchard and 0 . H. Hicham, "Catalytic properties of carbon nanofilaments produced by iron-catalysed reforming of ethanol," Chemical Engineering Journal, vol. 139, no. 3, pp. 532-539, 2008.

[15] B. Fidalgo, A. Arenillas and J. A. Menéndez, "Influence of porosity and surface groups on the catalytic activity of carbon materials for the microwaveassisted $\mathrm{CO}_{2}$ reforming of $\mathrm{CH}_{4}$," Fuel, vol. 89, no. 12, pp. 4002-4007, 2010.

[16] A. L. M. Da Silva, L. V. Mattos, J. P. den Breejen, J. H. Bitter, K. P. de Jong and F. B. Noronha, "Oxidative steam reforming of ethanol over carbon nanofiber supported Co catalysts," Catalysis Today, vol. 164, no. 1, pp. 262267, 2011.

[17] E. López, J. Kim, A. M. Shanmugharaj and S. H. Ryu, "Multiwalled carbon nanotubes-supported nickel catalysts for the steam reforming of propane," Journal of Materials Science, vol. 47, no. 6, pp. 2985-2994, 2011.

[18] Y. Xu, P. W. Jiang and Q. X. Li, "Carbon nanofiberssupported $\mathrm{Ni}$ catalyst for hydrogen production from bio-oil through low-temperature reforming," Acta Physico-Chimica Sinica, vol. 29, no. 5, pp. 1041-1047, 2013.

[19] R. Giordano, P. Serp, P. Kalck, Y. Kihn, J. Schreiber, C. Marhic and J. L. Duvai, "Preparation of rhodium catalysts supported on carbon nanotubes by a surface mediated organometallic reaction," European Journal of Inorganic Chemistry, vol. 2003, no. 4, pp. 610-617, 2003. [20] Y. Li, G. H. Lai and R. X. Zhou, "Carbon nanotubes supported Pt-Ni catalysts and their properties for the liquid phase hydrogenation of cinnamaldehyde to hydrocinnamaldehyde," Applied Surface Science, vol. 253, no. 11, pp. 4978-4984, 2007.

[21] Z. J. Liu, Z. Xu, Z. Y. Yuan, D. Lu, W. Chen and W. Zhou, "Cyclohexanol dehydrogenation over Co carbon nanotube catalysts and the effect of promoter $\mathrm{K}$ on performance," Catalysis Letters, vol. 72, no. 3, pp. 203206, 2001. 
[22] P. K. Seelam, M. Huuhtanen, A. Sápi, M. Szabó, K. Kordás, E. Turpeinen, G. Tóth and R. L. Keiski, "CNTbased catalysts for $\mathrm{H}_{2}$ production by ethanol reforming," International Journal of Hydrogen Energy, vol. 35, no. 22, pp. 12588-12595, 2010.

[23] P. Serp, M. Corrias and P. Kalck, "Carbon nanotubes and nanofibers in catalysis," Applied Catalysis A: General, vol. 253, no. 2, pp. 337-358, 2003.

[24] H. Liu, G. Cheng, R. Zheng, Y. Zhao and C. Liang, "Influence of acid treatments of carbon nanotube precursors on Ni/CNT in the synthesis of carbon nanotubes," Journal of Molecular Catalysis A: Chemical, vol. 230, no. 1-2, pp. 17-22, 2005.

[25] A. Chambers, N. Tibor, N. M. Rodriguez and R. T. K. Baker, "Catalytic behavior of graphite nanofiber supported nickel particles. 1. Comparison with other support media," The Journal of Physical Chemistry B, vol. 102, no. 12, pp. 2251-2258, 1998.

[26] R. Gao, C. D. Tan and R. T. K. Baker, "Ethylene hydroformylation on graphite nanofiber supported rhodium catalysts," Catalysis Today, vol. 65, no. 1, pp. 19-29, 2001.

[27] N. Abatzoglou, F. Gitzhofer, D. Gravelle, J. Blanchard, K. DeOliveira-Vigier, H. Oudghiri-Hassani, H. Gauvin, "Carbon sequestration and dry reforming process catalysts to produce same". United States of America Patent 7794690 B2, 14 September 2010.

[28] J. Blanchard, O. H. Hicham, N. Abatzoglou, S. Jankhah and F. Gitzhofer, "Synthesis of nanocarbons via ethanol dry reforming over a carbon steel catalyst," Chemical Engineering Journal, vol. 143, no. 1-3, pp. 186194, 2008.

[29] C. Fauteux-Lefebvre, N. Abazoglou, N. Braidy and I. E. Achouri, "Diesel steam reforming with a nickelalumina spinel catalyst for solid oxide fuel cell application," Journal of Power Sources, vol. 196, no. 18, pp. 7673-7680, 2011.

[30] J. R. Regalbuto, "Strong electrostatic adsorption of metals onto catalyst supports," in Catalyst Preparation: Science and Engineering, CRC Press, 2006, pp. 297-318. [31] M. L. Toebes, M. P. Jürgen, H. Bitter, J. Dillen and K. P. de Jong, "The influence of oxidation on the texture and the number of oxygen-containing surface groups of carbon nanofibers," Carbon, vol. 42, no. 2, pp. 307-315, 2004.

[32] A. Mahajan, A. Kingon, Á. Kukovecz, Z. Konya and P. M. Vilarinho, "Studies on the thermal decomposition of multiwall carbon nanotubes under different atmospheres," Materials Letters, vol. 90, pp. 165-168, 2013. 